09;14

\title{
Рамановское рассеяние света высокого спектрального разрешения в метформине
}

\author{
(C) Ф.Б. Байрамов ${ }^{1}$, В.В. Топоров ${ }^{2}$, О.Б. Чакчир ${ }^{1}$, \\ B.Н. Анисимов ${ }^{1,3}$, Б.Х. Байрамов ${ }^{2, \uparrow}$
}

${ }^{1}$ Санкт-Петербургский национальный исследовательский академический университет РАН, Санкт-Петербург, Россия

${ }^{2}$ Физико-технический институт им. А.Ф. Иоффре РАН, Санкт-Петербург, Россия

${ }^{3}$ Национальный медицинский исследовательский центр онкологии им. Н.Н. Петрова, Санкт-Петербург, Россия

ฯ E-mail: bairamov@mail.ioffe.ru

Поступило в Редакцию 14 февраля 2018 г.

Получены спектры молекулярных колебаний высокого спектрального разрешения высокочувствительным методом рамановского рассеяния света в метформине - одном из наиболее применяемых современных антидиабетических препаратов, который обладает также способностью замедлять старение и препятствовать развитию злокачественных опухолей. Показано, что спектральные линии, обнаруженные в диапазоне частот $300-1200 \mathrm{~cm}^{-1}$, могут быть довольно узкими $\left(4-10 \mathrm{~cm}^{-1}\right)$, достаточными для выделения спектральных составляющих, соответствующих колебаниям отдельных молекул функциональных групп. Это вызывает особый интерес к метформину для использования его в качестве модели молекулярных биосенсоров.

DOI: $10.21883 /$ PJTF.2018.12.46284.17252

Препарат метформин гидрохлорид с двумя метильными группами в одном конце (химическая формула $\mathrm{C}_{4} \mathrm{H}_{11} \mathrm{~N}_{5} \cdot \mathrm{HCl}$ ), впервые обнаруженный во французской сирени (Галега лекарственная, Galega officinalis), 
представляет собой одно из наиболее эффективных лекарственных средств класса антидиабетических бигуанидинов - органических coединений, являющихся производными бесцветного кристаллического вещества гуанидина $\left(\mathrm{CH}_{5} \mathrm{~N}_{3}\right)$ [1,2]. Метформин широко используется во всем мире для лечения пациентов с сахарным диабетом второго типа в сочетании с ожирением. Помимо этого он является одним из двух пероральных противодиабетических препаратов, включенных в Примерный перечень основных лекарственных средств Всемирной организации здравоохранения (World Health Organization's Model List of Essential Medicines) [3]. Он также способствует улучшению утилизации глюкозы в тканях, снижению использования организмом жирных кислот в качестве энергетического субстрата, снижению концентрации в крови холестерина, триглицеридов и инсулина и, кроме того, уменьшению массы тела [1-4]. В последние годы показано геропротекторное, антиканцерогенное и противоопухолевое действие метформина [4-9]. Метформин также считается одним из лучших средств для профилактики сердечно-сосудистых осложнений сахарного диабета [1-5,9]. Вместе с тем препарат может обладать ограниченным количеством нежелательных побочных эффектов [5,9].

Молекулы метформина также представляют большой интерес для функционализации полупроводниковыми наноструктурами. Такие структуры имеют большое значение для наноконструирования самых разных гибридных устройств. В настоящее время это направление бионанотехнологии находит важное практическое приложение в биосенсорике и адресной доставке лекарственных средств к клеткам-мишеням. Ясно, что правильный дизайн, синтез и степень чистоты молекул метформина, определяющих как его самостоятельную активность, так и активность в составе комплексов, имеют решающее значение.

Даже при таком кратком описании препарата ясно, что, несмотря на широкий спектр лечебной активности и хорошие результаты лечения метформином, сложные физико-химические механизмы его действия в целом остаются не до конца понятыми $[1,4,6,8]$. Для более широкого использования препарата необходимы новые исследования, включая и разработки эффективных методов контроля молекулярной структуры метформина. Кроме того, проблема получения высокочистого метформина представляется очень важной как для научных, так и для практических целей. Поэтому актуальной задачей является необходимость развития и разработки новых эффективных методов исследования

Письма в ЖТФ, 2018, том 44, вып. 12 
структуры метформина на молекулярном уровне. Одним из эффективных аналитических методов исследования структуры таких сложных систем на молекулярном уровне служит спектроскопия рамановского рассеяния света.

В настоящей работе приводятся результаты исследования кристаллического метформина. Экспериментальные исследования выполнены с помощью развитой методики спектроскопии рамановского рассеяния света, характеризующейся высоким спектральным и пространственным разрешением, а также высокой чувствительностью регистрации спектров. Они позволили обнаружить сложные спектры изучаемых комплексов и, что особенно важно, выявить узкие спектральные линии, соответствующие отдельным молекулярным группам метформина.

Полученные результаты показывают, что разработанная альтернативная высокочувствительная методика спектроскопии рамановского рассеяния света высокого спектрального разрешения может быть использована для изучения молекулярной структуры и выяснения химической природы межмолекулярных и внутримолекулярных взаимодействий в метформине.

Измерения спектров рамановского рассеяния света выполнены на слабо спрессованных таблетках порошка метформина 1,1-Dimethylbiguanide hydrochloride белого цвета производства фирмы MP Biomedicals (Солон, Огайо, США) при комнатной температуре. Возбуждение спектров рамановского рассеяния света осуществлялось излучением второй гармоники лазера на основе алюмоиттриевого граната с длиной волны $\lambda_{i}=532 \mathrm{~nm}$ по методике, приведенной в [10-12]. Спектральный состав рассеянного света анализировался с помощью спектрометра LabRAM HR800 (Франция) с охлаждаемой CCD-матрицей в качестве детектора. Спектральное разрешение составляло $2 \mathrm{~cm}^{-1}$.

Типичный спектр рамановского рассеяния света в метформине, полученный нами в диапазоне частот $100-1200 \mathrm{~cm}^{-1}$ при комнатной температуре, приведен на рисунке. Экспериментальные результаты демонстрируют, что достигнутые высокое спектральное и пространственное разрешение и высокая чувствительность методики регистрации спектров рамановского рассеяния света оказались достаточными для выделения спектральных составляющих, соответствующих колебаниям отдельных молекул [12-14]. Спектры последних определяются пространственной структурой, задаваемой большим числом входящих в примитивную ячейку атомов, совершающих колебания относительно

Письма в ЖТФ, 2018, том 44, вып. 12 


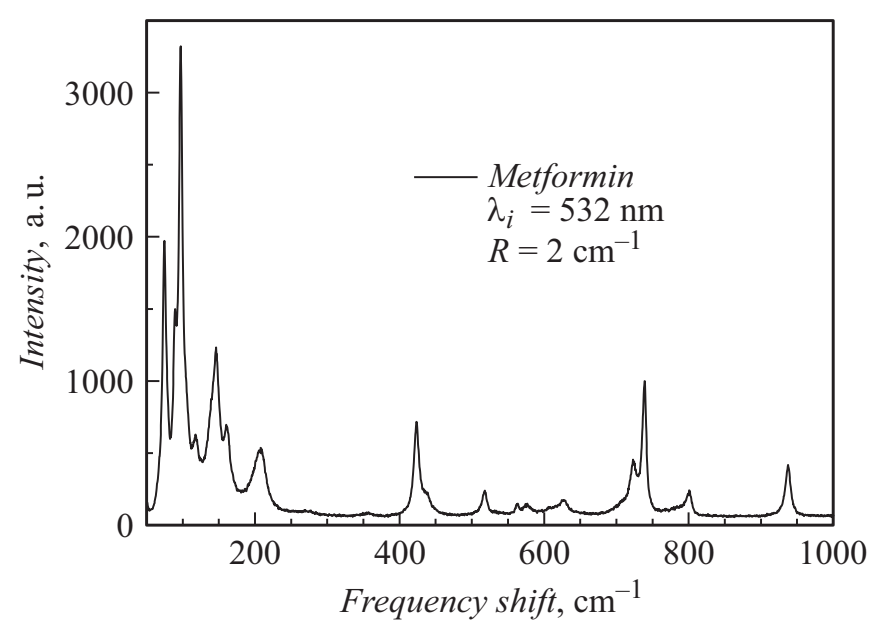

Экспериментальный спектр рамановского рассеяния света в слабо спрессованных таблетках метформина в диапазоне частот $100-1200 \mathrm{~cm}^{-1}$. Спектр получен при комнатной температуре. Спектральное разрешение составляло $2 \mathrm{~cm}^{-1}$.

положений равновесия. Макромолекулы таких соединений, как и макромолекулы белков, не содержат ни центров инверсии, ни зеркальной симметрии. В целом структурное упорядочение таких систем является результатом низкой симметрии их элементарных ячеек, обладающих винтовой или хиральной асимметрией [15]. В спектрах рамановского рассеяния света таких макромолекул должны наблюдаться сильно перекрывающиеся спектральные вклады, генерируемые большим набором атомов. Изменения спектральных параметров должны наблюдаться и для всех функциональных групп, испытывающих также влияние парных взаимодействий и окружающей среды. Полученные результаты свидетельствуют о высокой воспроизводимости экспериментальной методики и обнаружении довольно интенсивных и удивительно узких спектральных линий. Так, полуширина (полная ширина на половине ее высоты) линии при $935.8 \mathrm{~cm}^{-1}$, которую можно приписать маятниковым валентным колебаниям функциональной группы связи $\mathrm{N}-\mathrm{H}$ [16], равна $5 \mathrm{~cm}^{-1}$. Интенсивность фона мала, также мало и влияние сигнала от стеклянной подложки.

Письма в ЖТФ, 2018, том 44, вып. 12 
В целом полученные экспериментальные данные по обнаружению спектров рамановского рассеяния света в кристаллическом метформине демонстрируют, что достигнутые высокое спектральное разрешение и чувствительность регистрации позволили обнаружить в диапазоне частот $300-1200 \mathrm{~cm}^{-1}$ довольно узкие четко выраженные линии. Они достаточны для выделения спектральных составляющих, соответствующих колебаниям отдельных молекул метформина с довольно большим числом атомов в элементарной ячейке. Так, полуширина линии при $935.8 \mathrm{~cm}^{-1}$, соответствующей валентным колебаниям связи $\mathrm{N}-\mathrm{H}$, оказалась равной $5 \mathrm{~cm}^{-1}$. Такое обнаружение вызывает особый интерес к метформину для его практического использования в качестве удачных моделей молекулярных биосенсоров.

Таким образом, развитие новых спектральных методов эффективного исследования метформина на основе рамановского рассеяния света наряду с отмеченным выше самостоятельным интересом изучения его структуры на молекулярном уровне как эффективного лекарственного препарата представляет также большой интерес для создания нового класса низкоразмерных наноструктур [17-20] — нанобиогибридных комплексов полупроводниковых наноструктур, функционализированных метформином.

Работа выполнена при поддержке программы Президиума РАН I.7 „Актуальные проблемы фотоники, зондирование неоднородных сред и материалов“", а также в рамках государственного задания Министерства образования и науки РФ (16.9790.2017/БЧ).

\section{Список литературы}

[1] Anisimov V.N. // Anti-aging drugs: from basic research to clinical practice. RCS Drug Discovery Ser. N 57 / Ed. A.M. Vaiserman. London: The Royal Society of Chemistry, 2017. P. 416-431.

[2] Romero R., Erez O., Huttermann M., Maymon E., Panaitescu B., CondeAgudelo A., Pacora P., Yoon B.H., Grossman I.L. // Am. J. Obstet. Gynecol. 2017. V. 217. N 3. P. 282-302.

[3] WHO Model List of Essential Medicines. 16th ed. World Health Organization, 2010. 39 p.

[4] Martin-Castillo B., Vazquez-Martin A., Oliveras-Ferraros C., Menendez J.A. // Cell Cycle. 2010. V. 9. N 6. P. 1057-1064.

[5] Berstein L.M. // Aging (Albany NY). 2012. V. 4. N 5. P. 320-329.

Письма в ЖТФ, 2018, том 44, вып. 12 
[6] Viollet B., Guigas B., Sanz Garcia N., Leclerc J., Foretz M., Andreelli F. // Clin. Sci. (Lond.). 2012. V. 122. N 6. P. 253-270.

[7] Anisimov V.N. // Oncotarget. 2015. V. 6. P. 39398-39407.

[8] Anisimov V.N. // Interdisciplinary topics in gerontologi. Karger, 2015. V. 40. P. $177-188$.

[9] Bannister C.A., Holden S.E., Jenkins-Jones S., Morgan C.L., Halcox J.P., Schernthaner G., Mukherjee J., Currie C.J. // Diabet. Obes. Metab. 2014. V. 16. N 11. P. 1165-1173.

[10] Bayramov F.H., Irmer G., Toporov V.V., Bairamov B.H. // Jpn. J. Appl. Phys. 2011. V. 50. N 5S2. P. 05FE06.

[11] Байрамов Ф.Б., Топоров В.В., Полоскин Е.Д., Байрамов Б.X., Rödеr C., Sprung C., Bohmhammel K., Sidel J., Irmer G., Lashkul A., Lahderanta E., Song Y.M. // ФТП. 2013. Т. 47. В. 5. C. 608-612.

[12] Байрамов Ф.Б., Полоскин Е.Д., Корнев А.А., Чернев А.Л., Топоров В.В., Дубина M.B., Roder C., Sprung C., Lipsanen H., Байрамов Б.Х. // ФТП. 2014. T. 48. B. 11. C. 1521-1525.

[13] Байрамов Ф.Б., Полоскин Е.Д., Чернев А.Л., Топоров В.В., Дубина М.В., Lahderanta E., Lashkul A., Lipsanen H., Байрамов Б.Х. // Письма в ЖТФ. 2014. T. 40. B. 8. C. 44-49.

[14] Байрамов Ф.Б., Полоскин Е.Д., Корнев А.А., Чернев А.Л., Топоров В.В., Дубина M.B., Roder C., Sprung C., Lipsanen H., Байрамов Б.X. // Письма в ЖТФ. 2014. Т. 40. В. 22. C. 105-110.

[15] Kitaev Yu.E., Panfilov A.G., Smirnov V.P., Tronc P. // Phys. Rev. E. 2003. V. 67. N 1. P. 011907.

[16] Renganayaki V., Srinivasan S. // Int. J. PharmTech Res. 2011. V. 3. N 3. P. 1350 1358.

[17] Bairamov B., Toporov V., Bayramov F., Lanzov V., Dutta M., Stroscio M.A., Irmer G. // J. Phys.: Conf. Ser. 2007. V. 93. P. 012046.

[18] Байрамов Б.Х. // ФТТ. 2016. Т. 58. В. 4. С. 707-713.

[19] Байрамов Ф.Б., Полоскин Е.Д., Чернев А.Л., Корнев А.А., Топоров В.В., Дубина М.В., Байрамов Б.Х. // ФТП. 2017. Т. 51. В. 10. С. 1376-1381.

[20] Байрамов Ф.Б., Полоскин Е.Д., Чернев А.Л., Корнев А.А., Топоров В.В., Дубина M.В., Sprung C., Lipsanen H.К., Байрамов Б.Х. // Письма в ЖТФ. 2018. T. 44. B. 2. C. $72-78$. 